\section{LOS GATOS EN LA POÉTICA UMBRALIANA: REFLEJOS FELINOS DE BAUDELAIRE}

\author{
José Antonio Soto Cruz \\ Universidad Nacional de Educación a Distancia \\ conde.josesoto@gmail.com \\ Lara Mantoanelli Silva \\ Universidade de São Paulo \\ larafms@gmail.com
}

Cómo citar este artículo/Citation: Soto Cruz, J. A. y Mantoanelli Silva, L. (2015). "Los gatos en la poética umbraliana: reflejos felinos de Baudelaire". Arbor, 191 (774): a247. doi: http:// dx.doi.org/10.3989/arbor.2015.774n4002

Recibido: 11 marzo 2014. Aceptado: 26 septiembre 2014

RESUMEN: Es conocida la admiración de Francisco Umbral por la vida y la obra de Charles Baudelaire, y la podemos ver en innumerables textos, columnas, entrevistas y poemas. En este artículo establecemos la relación entre ambos a través de la figura del gato y lo que este animal significa en sus respectivas obras. Pues para los dos escritores, más que un felino, el gato también simboliza lo femenino, lo divino, la sabiduría y el tiempo.

PALABRAS CLAVE: Umbral; Baudelaire; gato; mujer; esfinge; sabiduría; mitología; eternidad; tiempo.

\section{CATS IN UMBRAL'S POETICS: FELINE REFLECTIONS OF BAUDELAIRE}

Copyright: (c) 2015 CSIC. Este es un artículo de acceso abierto distribuido bajo los términos de la licencia Creative Commons Attribution-Non Commercial (by-nc) Spain 3.0.
ABSTRACT: It is Francisco Umbral's admiration for the life and works of Charles Baudelaire is well known, and we can see it in countless texts, columns, interviews and poems. In this article we establish the relationship between the poets through the figure of the cat and what this animal means in their respective works. For both writers the cat was more than an animal, symbolising the feminine, the divine, wisdom and time.

KEYWORDS: Umbral; Baudelaire; cat; woman; sphinx; wisdom; mythology; eternity; time. 
"El gato ha sido el animal totémico de mi vida" (Umbral, 1998), dijo Francisco Umbral en una de sus columnas del Diario con Guantes, publicada en el periódico El Mundo. Efectivamente, podemos comprobar su profunda admiración hacia este animal en innumerables textos, artículos, entrevistas y poemas. Repetidas veces, Umbral vuelve al gato como un símbolo íntimo de la naturaleza, como si el origen y destino de toda la humanidad estuvieran en los ojos gatunos de misterio y capricho, como si el felino fuese el resumen de su vida y de su literatura, que, para el escritor, vienen a ser lo mismo. Pero el enfoque con el que trata el gato siempre estuvo marcado por una afilada perspectiva lírica que, sabemos, viene con el sello de Charles Baudelaire. La influencia del poeta francés la advertimos en varios temas recurrentes de su obra: el dandismo y sus espejos, la relación con la ciudad, las mujeres, la condición de niño huérfano, y también la fascinación por los gatos. En este breve estudio profundizaremos en qué medida los felinos baudelerianos condicionan la poética del escritor español.

En las Flores del Mal existen tres poemas dedicados enteramente al gato, $y$, junto a la mujer, el vino, el tiempo, la muerte y el spleen, configura uno de los grandes temas del libro. También en los Pequeños poemas en prosa notamos la presencia del felino. Lo curioso, y auténticamente inquietante, es que en cada aparición, el animal adquiere un nuevo significado: sensualidad, misterio y eternidad son algunas de sus facetas.

La primera figura -y quizás la más obvia- en la que se convierte el gato baudeleriniano nos la revelan Román Jakobson y Claude Lévi-Strauss cuando dicen, en el estudio estructuralista sobre el poema "Los gatos", que, "para Baudelaire, la imagen del gato está ligada estrechamente a la de la mujer" (Jakobson y Lévi-Strauss, 1970, p. 33). Hay continuas e inequívocas referencias a las amantes Jeanne Duval y Marie Daubrun cuando habla de los gatos. Sobre la mulata Jeanne Duval, bailarina y actriz, estas alusiones se dan por su cuerpo negro que danza y hechiza al poeta, por su enigma de mujer estéril, por su útero inútil y bello. En el poema "El gato" vemos claramente esta aproximación: "Cuando a gusto mis dedos acarician tu cabeza (...) veo el fantasma de mi amor" (Baudelaire, 1993, p. 179), y termina el poema diciendo que los ojos de su amante, al igual que los del gato, "nadan en torno al cuerpo bruno" (Baudelaire, 1993, p. 179), mención evidente a la mulata Duval. En otro poema, igualmente titulado "El gato", el animal se funde con la imagen de Marie: "Por mi cerebro se pasea,/ lo mismo que por su aposento,/ un bello gato" (Baudelaire,
1993, p. 231). Con esos versos nos queda clara la idea del poeta de la doble significación del animal, pues es, al mismo tiempo, el gato de Marie y la propia Marie. Nos confirma tal sugerencia cuando describe al felino por "su piel rubia y morena" (Baudelaire, 1993, p. 233), una referencia explícita al pelo rubio rojizo que tenía su amante.

Francisco Umbral también, a menudo, relaciona la imagen del gato a la de la mujer, pero lo hace por medio de metonimias, la parte por el todo: pechos, orejas, miradas. Por ejemplo, cuando dice en el poema "Leticia y el portero canceroso": "hasta llegar a sus pechos, (...) que habían sido heroicos (...) pero se empequeñecían bajo mi mano como un gato" (Umbral, 2009, p. 76). O en Un ser de lejanías, cuando indica que "el sexo, a veces nos conduce a habitaciones asirias, o a altísimos pisos donde hay una niña en llamas con orejas de gato" (Umbral, 2001, p. 184). En el sexo, las partes de la mujer - sus pechos y orejas - adquieren formas felinas. La relación entre ellas y los gatos es tan íntima que Umbral incluso llega a postular que "conoce uno el gremio de los gatos casi como el gremio de las señoritas" (Umbral, 2008, p. 88). Interesante también verificar que el escritor ha tenido varias gatas de sexo femenino - Ada, Loewe, Candy - y les dio especial atención en sus textos.

Otro punto que habría que resaltar es que Charles Baudelaire utiliza frecuentemente el oxímoron, una figura literaria que consiste en confrontar dos ideas antagónicas entre sí en una misma expresión, generando un tercer concepto novedoso, como es evidente en el título Las flores del mal. Esa misma figura la utiliza cuando habla de los gatos: Ilama "amable fiera" (Baudelaire, 1993, p. 179) al felino, lo describe como "dulce y fuerte" (Baudelaire, 1993, p. 231), o incluso dice "con estupor contemplo el fuego/ de sus tan pálidas pupilas" (Baudelaire, 1993, p. 233). Tales contrastes entre una idea de fragilidad, dulzura, palidez y amabilidad, y otra de fuerza, poder, ardor y salvajismo, configuran para el poeta la imagen general del animal. El gato será, pues, la suma de esos opuestos, la síntesis que siempre se revela en su poética como la condición íntima de la belleza. Los amantes, la muerte, la ciudad, la luna, los gatos son elementos que se nos presentan en Las flores del mal, a menudo, a través de elementos contrarios y contradictorios, y precisamente por esto, logran alcanzar una nueva dimensión de significado, un tercer concepto misterioso e inalcanzable, que es el ámbito inherente a lo bello, como dice en Diarios íntimos: "del aire en la mujer: los aires encantadores que hacen belleza son: (...) el aire gatuno, puerilidad, aban- 
dono y malicia mezclados" (Baudelaire, 2006, p. 27). Elementos tan antagónicos como puerilidad, abandono y malicia constituyen el aire felino de belleza que tiene la mujer. Esa unión de contrarios es el centro de la idea baudeleriana, revelándonos que "éste es uno de los caracteres más interesantes de la Belleza - el misterio" (Baudelaire, 2006, p. 25).

De la misma manera, Francisco Umbral usa el oxímoron al hablar del felino. Por ejemplo, cuando dice en Carta a mi mujer: "son domésticos, pero indomables" (Umbral, 2008, p. 140); o también, "mis dos gatos (...) son los únicos vectores de verdad natural que hay en mi vida. De ellos me llega lo poco o lo mucho que me llega de la vida. De su vivir salvaje, coherente y errabundo" (Umbral, 2008, p. 48). El escritor afirma en otro momento que "mi gata, Ada o el ardor, ingenua y niña, sabe más del jardín, del cielo y de la tierra, del mundo, de la naturaleza, que todo lo que nosotros podamos deducir" (Umbral, 2008, p. 43). Ada reúne en sí la ingenuidad infantil y, a la vez, una sabiduría superior a la humana (tema que trataremos detalladamente más adelante). Si por un lado son domésticos, coherentes, ingenuos, por otro, indomables, salvajes, errabundos y sabios. Estos antagonismos también generan, en la poética umbraliana, una síntesis de belleza y misterio.

Si antes hemos dicho que frecuentemente se relaciona la figura del gato a la mujer, y ahora consideramos el uso continuo del oxímoron, llegamos a la propuesta presente en ambas poéticas: el felino estaría dotado de cierta androginia, de un aura de ambigüedad en su naturaleza. El animal tendría la dulzura y la delicadeza femeninas, pero también la fuerza y el poder masculinos (siguiendo los tópicos culturales que conllevan esas categorías). Michel Butor, en la Histoire extraoidinaire, essai sur un rêve de Baudelaire postula con gran acierto que para el poeta "esos dos aspectos: femineidad y supervirilidad lejos de excluirse recíprocamente, están ligados entre sí" (Jakobson y Lévi-Strauss, 1970, p. 33). Igualmente Jakobson y LéviStrauss llaman la atención sobre este punto en el poema "Los gatos", observando que "todos los personajes del soneto son de género masculino, pero les chats (los gatos) y su alter ego, les grands sphinx (las grandes esfinges), participan de una naturaleza andrógina" (Jakobson y Lévi-Strauss, 1970, p. 34). Este sería el máximo oxímoron de los felinos para Baudelaire, "los gatos, poderosos y dulces" (Baudelaire, 1993, p. 281), son masculinos y femeninos a la par.

Curioso ver cómo Umbral también recurre a esta imagen en La fábula del falo cuando versa sobre "el falo/felino". Dice: "observo la conducta fálica de mis gatos. El gato, aparte la masturbación (...), o después de la fornicación, se separa, se aísla para lamer, chupar, aliviar, disfrutar su propio y diminuto falo rojo" (Umbral, 1985, p. 31). Y sigue su teoría diciendo que, como el hombre es el único mamífero que no alcanza oralmente a su miembro, su salvación estaría en otras bocas: "El problema se ha resuelto mediante la otra mitad humana, la hembra, que sí disfruta del falo del macho. (...) Que disfruta bucalmente, quiero decir" (Umbral, 1985, p. 33). Nos queda clara la alusión directa a la propuesta del poeta francés: el gato sería la suma de lo que para lo humano son naturalmente insumables, sería el mamífero andrógino por excelencia.

Más allá de la oposición meramente humana, Baudelaire se cuestiona sobre la naturaleza angélica de los felinos. En el poema "El gato", él revela esta idea cuando dice "gato seráfico y extraño,/ en quien todo es, como en un ángel,/ tan armonioso cuan sutil" (Baudelaire, 1993, p. 231). Compara el felino a la figura del serafín, desprovisto de sexo definido, ser mítico, humano, ángel, bello y alado. Un poco después, Baudelaire vuelve a tal duda: “¿tal vez es hada, tal vez dios?” (Baudelaire, 1993, p. 233). Igualmente, en el soneto "Los gatos", los compara a las esfinges: "adquieren, mientras sueñan, las nobles actitudes/ de esfinges que se alargan allá en sus soledades" (Baudelaire, 1993, p. 281). Sabemos que estos seres, con cuerpo de felino, faz de mujer y alas, simbolizan el enigma, el misterio y la sabiduría, como trataremos más adelante. Para Baudelaire, el gato encerraría, pues, en sí, las figuras de mujer, andrógino, ángel, esfinge, hada y dios. Su condición, inevitablemente, es la de síntesis de todos esos antagonismos; el oxímoron máximo de la naturaleza es el misterio que serpentea en su cola felina.

Ya hemos visto cómo Umbral sigue la misma línea del poeta francés al dotar de significado al animal por la relación que establece con la mujer, con el ser andrógino, capaz de lamer su propio falo, y también con las esfinges. Dice Umbral en Un ser de lejanías: "Amo a mi honda gata (...), todo el diseño egipcio de su cuerpo" (Umbral, 2001, p. 164). Las esfinges, con cuerpo felino y rostro femenino, sintetizan en su propia forma todo el enigma y las contradicciones vistas anteriormente. El escritor español desarrolla parte de su planteamiento en La fábula del falo cuando dedica un capítulo entero a la "Mujer fálica": "La fecundación de la mujer, mítica o no, como afán fálico se explica en muchos casos no explicados por la necesidad de destruir el enigma. El hombre fálico no soporta el enigma de lo femenino, y su manera casi homicida de resolverlo es destruirlo. (...) La mujer (...) a todos se 
nos ha hecho intolerable por inquietante, por desazonante, y el precario triunfo del falo sobre este enigma es la fecundación. La amazona preñada, la Esfinge preñada, destruida en su perfil hermético, deforme, deja de ser esfíngica. El enigma se resuelve en madre y el falo se queda tranquilo. Ya que no ha descifrado a la mujer, la ha destruido (de ahí que no la descifre jamás)." (Umbral, 1985, p. 119).

El mismo título de este capítulo, "Mujer fálica", ya nos indica la condición andrógina de tales féminas, y su perfil hermético, esfíngico. La mujer fálica tendría, pues, en su naturaleza, una mitad felina. En el mismo libro, Umbral dedica igualmente un capítulo al "Falo/ Baudelaire" que, "según todos los datos disponibles, era impotente" (Umbral, 1985, p. 17), así que "el falo/ Baudelaire, en todo caso, es el falo suntuoso, imaginativo e inútil" (Umbral, 1985, p. 19). Umbral Ilama la atención a la infuncionalidad del miembro del poeta francés: "la condición lujosa de Baudelaire es su condición ociosa" (Umbral, 1985, p. 18), afirma. Pues bien, si la mujer esfíngica (mitad fémina, mitad felina) suscita al enigma, la manera de destruir el misterio que habita en su cuerpo, en su mirada, en su propia naturaleza, es fecundándola. Y si consideramos que el falo/Baudelaire es impotente, ocioso e inútil, tendremos la ecuación de que el miembro del poeta respeta y acepta el misterio femenino/felino que existe como tal. No lo quiere destruir ni tampoco descifrarlo, sino que se deleita en los laberintos secretos y enigmáticos de su naturaleza. Francisco Umbral llega a afirmar que "ahora (y ya ha quedado dicho) es cuando el falo resulta lujoso, ocioso, como Baudelaire y como sus gatos, incluso, belleza inútil, referencia icónica, signo intolerable del erotismo y el juego" (Umbral, 1985, p. 17) El falo deja de ser funcional para convertirse en signo, para convertirse en un elemento lujoso del juego erótico. El erotismo se opone a la fecundación, así como la mujer/enigma, la mujer/gato, "la mujer fálica" -como la llamó Umbral-, se opone completamente a la mujer/madre. El falo/ Baudelaire es el que posibilita esta relación estéril y de belleza inútil, condición última de los felinos, la suma de lo masculino y lo femenino.

Volviendo a la semejanza de los gatos a las esfinges, hacemos referencia de nuevo a los versos de Baudelaire donde se nos dice que estos animales "adquieren, mientras sueñan, las nobles actitudes/de esfinges que se alargan allá en sus soledades" (Baudelaire, 1993, p. 281). Cierto es, como oportunamente señalaron Jakobson y Lévi-Strauss en su comentario al poema "Los gatos", que en Baudelaire "los gatos parecen identificarse con las esfinges" (Jakobson y Lévi-Strauss, 1970, p. 24). La primera afinidad, la más obvia sin duda, es con respecto a la naturaleza gatuna de ambos, puesto que, como ya hemos señalado, las esfinges tienen rostro de mujer, alas de ave y cuerpo de felino; e incluso, habitualmente en la iconografía general aparecen tumbadas con las patas delanteras extendidas, coincidiendo con la postura más típica de los gatos. Pero si vamos más allá de las comparaciones físicas, llegamos a que, para Baudelaire, detrás de cada gato, al igual que pasa con las esfinges, hay un secreto, una adivinanza, un acertijo, un extraño enigma que descifrar. Y precisamente es en ese misterio del que hablamos, en esta pregunta, donde reside la gran identificación entre ellos.

Asimismo, Théophile Gautier, en el prólogo de Las Flores del Mal, nos asegura que Baudelaire "amaba a estos encantadores animalitos, tranquilos, misteriosos y dulces, con estremecimientos eléctricos y cuya actitud favorita es la postura extendida de las esfinges, que parecen haberles transmitido sus secretos" (González-Ruano, 2008, p. 111). Insistiendo en el gato como enigma, como ser que guarda dentro de sí un misterio vedado a los hombres, no es de extrañar, pues, que en otro poema Baudelaire hable de "gato misterioso" (Baudelaire, 1993, p. 233). El adjetivo "misterioso" lo arraiga a ese terreno de lo desconocido, como portador de una verdad escondida, recóndita, ignota, secreta, y lo devuelve - o lo enlaza - a la figura enigmática de la esfinge.

Igual significado reviste este animal en los textos de Francisco Umbral. Es más, en un poema titulado "La gata y la nieve" nos habla de "misterioso gato" (Umbral, 2008, p. 170). De modo que él define al felino de la misma manera que ya hizo Baudelaire ("gato misterioso"), solo que la diferencia es que antepone el adjetivo al nombre, lo vuelve explicativo. Con este pequeño cambio de posición, Umbral quiere poner todavía más énfasis en que la cualidad de "misterioso" es propia a todo gato, que debe ser aplicada al conjunto de estos animales. Todos los felinos de Umbral y de Baudelaire -"gato misterioso" y "misterioso gato"- tienen algo oculto, son indescifrables, atesoran una pregunta, una interrogación, una incógnita que fascina a los dos escritores.

En otro poema, "Los gatos", el escritor español nos dice: "Siempre miraré al gato (...) y esa interrogación que hay en su rabo" (Umbral, 2008, p. 167). Cuando Umbral mira al gato, lo hace con ojos baudelerianos, y se centra sobre todo en lo ilegible de él, en lo que no se le ve, en lo que solo se intuye, se sospecha. Esa fantasmal interrogación escurridiza y callada, íntima 
y sigilosa del gato, es verdaderamente el enigma que persigue el escritor.

En las siguientes citas, Umbral continúa con la misma idea: "me queda solo un gato/como un signo" (Umbral, 2008, p. 159), "el gato es un asterisco o un señor egipcio que se ha quedado a vivir con nosotros" (Umbral, 2000), "no está muy claro si el gato es un animal o un príncipe chino" (Umbral, 2000), "el gato es un animal aristocrático, egipcio y faraónico, que el pueblo no acaba de entender" (Umbral, 1999, p. 354). Signo, asterisco, señor egipcio, príncipe chino y animal faraónico son algunos ejemplos de lo indescifrable que puede llegar a ser el gato para él. Digamos que Francisco Umbral entiende, como Baudelaire, que lo fundamental de este animal, lo puramente innato en él, es esa imagen borrosa y difuminada que nos transmite. Hay algo en el gato que se les escapa a ambos, y eso es, como queda dicho, verdaderamente lo que más les atrapa del felino. Y en cierto sentido, lo que más les une a él. Desde esta perspectiva, como señalamos anteriormente, no sorprende que Baudelaire, en sus Diarios Íntimos, diga que el misterio es también una característica de lo Bello. O sea: la mirada huidiza y profunda del gato, lo imprevisible de su paso, su independencia y la libertad de su personalidad, son ante todo atributos que, de alguna manera, para el autor de Las flores del mal, y también para Umbral, llevan a este animal al orden superior de la Belleza.

La relación entre la esfinge y el gato se pone de manifiesto no solo en relación al misterio que ya hemos señalado aquí, sino también en la clara sabiduría que los dos seres parecen simbolizar. Volviendo atrás en el tiempo, recordemos que la esfinge, ya fuera en el antiguo Egipto o en la Grecia clásica, era la encargada de custodiar toda la sapiencia contenida en la naturaleza. Tal privilegio, único y extraordinario, a la vez que mágico y monstruoso, le confería amplios poderes sobre la vida y la muerte. Esta sabiduría milenaria es, asimismo, la que parecen tener los gatos de estos escritores. Francisco Umbral nos dice: "Mi gata (...) sabe más del jardín, del cielo y de la tierra, del mundo, de la naturaleza, que todo lo que nosotros podamos deducir" (Umbral, 2008, p. 43). Así, tenemos la impresión de que el gato guarda celosamente en sus ojos un saber que, en definitiva, solo él posee. "El gato parece conocer la última crónica del sábado" (González-Ruano, 2008, p. 112), dice Gautier sobre la fascinación de Baudelaire hacia ellos. $Y$ es que, el gato tiene una sabiduría inherente a su naturaleza; es como si en él se hubiera vertido todo el conocimiento de la esfinge. La concordancia de ambos seres se impone sola.
En este punto, parece ya inevitable elevar, pues, el gato a la categoría de mito. Misterio, enigma, sabiduría, son todas ellas características que lo posicionan como un animal sagrado $y$, por consiguiente, como un ser divino. Tengamos en cuenta de nuevo las palabras de Baudelaire: “¿tal vez es hada, tal vez dios?" (Baudelaire, 1993, p. 233). De otra manera, pero con el mismo sentido, se expresa Umbral cuando dice: "En mi afán por huir de lo humano peor (...) he venido en descubrir que la verdadera y realísima mitología son los animales" (Umbral, 2001, p. 216). Y en otro texto equipara la urraca al águila y la pantera al gato: "La pantera y el águila en versión doméstica, abreviada, pero, para ellos, igualmente mitológica. La urraca es el Ave Fénix frente al león de las pirámides" (Umbral, 2001, p. 134). Es decir: ambos escritores apuntan, en puridad, que el gato pertenece a un territorio mítico, como si un hilo secreto, atravesando los siglos, lo uniera con el principio de los tiempos.

Charles Baudelaire en uno de los Spleens nos indica claramente esta condición atemporal de las esfinges cuando dice: "vieja esfinge que el mundo indiferente ignora,/ olvidada en el mapa, y cuyo humor huraño/ solo canta a los rayos del sol cuando se pone." (Baudelaire, 1993, p. 301). El adjetivo "vieja" le confiere esa entereza en relación al tiempo. Ignorada y olvidada por el mundo, la esfinge resiste como un secreto divino todas las épocas y espacios. Con lo único que tiene una conexión eterna es con el sol, que simboliza el presente en estado puro. Cada atardecer, la esfinge canta a los rayos solares como una forma de culto al astro rey, por surgir este, infaliblemente, día tras día, repitiendo de esta manera la infinita duración de un instante, la actualidad perenne que se impone sobre el propio tiempo. Por lo tanto, la solitaria y huraña esfinge se reconoce en el sol por su naturaleza igualmente atemporal. Lo despide sabiendo que, en ese presente perpetuo, son semejantes, son hermanos.

Siguiendo con este mismo planteamiento, Francisco Umbral nos indica también la propiedad atemporal de los gatos: "Devuélveme la gata (...) a la inocencia del presente puro" (Umbral, 2008, p. 52), o cuando dice "la gata dibuja ochos entre mis piernas desnudas, (...) desde su presente absoluto y puro, desde su eternidad de vida al sol, jamás ensombrecida por la muerte. Detrás de cada ocho, la dulce rúbrica de su rabo." (Umbral, 2001, p. 204). Con el movimiento doblemente circular que hace entre sus piernas, la felina deja patente su natural inclinación hacia el infinito. Aquí, una vez más, el sol parece dialogar con la eternidad del gato, que es la suya misma. Quieto e hierático, un 
gato al sol es la máxima representación del tiempo absoluto, que no es otra cosa que el "no tiempo", o, simplemente, la Eternidad, que no posee ni presente, ni pasado y tampoco futuro, sino que es una larga línea continua y transparente que perdura en el aire. De este modo, la muerte no es capaz de hacer sombra ni al gato ni al sol.

Si volvemos al poeta francés, más concretamente al soneto Spleen LXXV (Baudelaire, 1993, p. 299), confirmamos este estado del "no tiempo" en el que existen los felinos, seres aptos para hacer frente a la propia muerte. En el poema, "el lúgubre frío" asola fatalmente la ciudad, como un aviso al fin último e inevitable de todos los mortales. Hay varios elementos que refuerzan este contexto siniestro: "gentes pálidas", "cementerio próximo", "la mortalidad en los barrios brumosos", "reloj resfriado". Todos ellos perecen bajo el yugo de "una hidrópica vieja", o sea, la insaciable muerte. Para todos los mortales, el encuentro con esta "hidrópica vieja" es una batalla perdida, sin embargo Baudelaire subvierte la lógica natural y aparta de ese trágico desenlace al gato y al poeta.

\section{"En el cojín mi gato buscando una yacija \\ agita su delgado cuerpo carnoso; el alma \\ de un antiguo poeta yerra en el canalón \\ con la voz dolorosa de un fantasma friolero" \\ (Baudelaire, 1993, p. 299)}

Absortos y ajenos a la luctuosa realidad, un felino busca descanso en un lecho improvisado en un cojín, y la voz fantasmal del poeta resiste el paso del tiempo y la mortalidad del cuerpo.

Quizás el texto baudeleriano más revelador de la relación de los felinos con el tiempo es "El reloj", un pequeño poema en prosa. En él, el poeta francés empieza diciendo que "los chinos ven la hora en los ojos de los gatos" (Baudelaire, 2013, p. 75), y cuenta la anécdota de un niño que supo que aún no era mediodía con solo mirar los ojos de un felino. Baudelaire relata a continuación que también él aplica el mismo método al mirar fijamente a una "bella Felina". Dice: "en el fondo de sus ojos adorables siempre veo con claridad la hora, constantemente la misma, una hora vasta, solemne, grande como el espacio, sin divisiones de minutos ni de segundos, una hora inmóvil que no está señalada en los relojes" (Baudelaire, 2013, p. 75). Además, señala que si alguien le preguntara qué ve, contestaría sin dudar: "veo la hora; ies la Eternidad!" (Baudelaire, 2013, p. 76). Baudelaire se queda atrapado en los ojos de una gata, en esa mirada profunda que habita el "no tiempo", una mirada fijada en la
Eternidad misma, entendida esta última como perpetuidad sin principio, sucesión ni fin.

Asimismo, César González Ruano en su biografía sobre Baudelaire nos matiza, con gran acierto, esta idea: "Baudelaire (...) debió comprender mejor que nadie (...) la mirada de los gatos llena tantas veces de infinito y femenil reproche, de presentimiento pavoroso también. (...) porque los ojos de los gatos guardan seguros y rencorosos, como espejos de cábala, el cuerpo de la mujer desnuda que nadie supo que tuvimos desnuda en nuestros brazos y la fotografía de nuestro rostro lívido en el momento de ser bestias y ser dioses con la cabeza llena de trapos sucios, ausentes de toda realidad" (González-Ruano, 2008, p. 113). Ahora sabemos cuál es el misterio, el enigma y la sabiduría que albergan estos animales. Pues, efectivamente, es el poeta francés quien mejor supo leer que, detrás de esos ojos vacíos de toda realidad, estaba guardado, como un secreto, la verdad del tiempo, o sea, su total ausencia.

En uno de sus poemas, "El diseño del gato", Umbral corrobora que este animal, capaz de viajar por las épocas, regresa a casa con la respuesta del enigma del tiempo. "Para conocer el mundo y sus aconteceres, nada como enviar un animal de vuelta a través de los tiempos. (...) Envié mi gato a través del infinito a descifrar del más allá el misterio (...), volvió a mí diciendo: yo soy cielo e infierno. (...) No hay animal, cosa, libro, mujer, viaje que pueda resumir la Historia de la humanidad, con toda su avilantez y variedad, como un gato flechado por el mundo" (Umbral, 2009, p. 112). La respuesta que trae el gato es su condición atemporal, su capacidad de viajar por las eras, ese pasearse por la historia de la humanidad, y condesar en su cuerpo pequeño todos los secretos que existen entre el cielo, la tierra y el infierno, entre la naturaleza humana, animal y divina. El gato sería la síntesis contraria y contradictoria, como un oxímoron, de toda la existencia del mundo.

Por último, es significativo que Gautier nos indique la íntima conexión que existe entre escritores y gatos al decir que estos últimos "vagan con aterciopelado paso por la casa como los genios del lugar - genius loci - o vienen a apelotonarse bajo la mesa, al lado del que escribe, haciendo compañía a su pensamiento (...) Diríase que los gatos adivinan la idea que desciende desde el cerebro a las puntas de la pluma y que, estirando su zarpa, quisieran atraparla al paso". (González-Ruano, 2008, p. 111). Los felinos son capaces, silenciosamente y con inteligente ternura, de comprender y compartir, mejor que cualquier otro 
ser, el oficio de la escritura. Acompañan con su mágica y penetrante mirada los pensamientos del escritor, que bajan desde el cerebro hasta la pluma.

De esta manera, no nos extraña que Baudelaire y Umbral revelasen el deseo profundo de convertirse ellos mismos en gatos. Por ejemplo, en el soneto "La giganta", Baudelaire nos confiesa que le habría gustado "haber vivido junto a una joven giganta, / como un gato sensual a los pies de una reina" (Baudelaire, 1993, p. 135). De hecho, según palabras de Gautier, el poeta logra su objetivo, pues "el mismo Baudelaire era un gato voluptuoso (...) fijando sobre las cosas y las personas una mirada de inquietante luz..." (González-Ruano, 2008 , p. 113). Este mismo deseo lo comparte Umbral cuando confiesa en Carta a mi mujer: "Ahora que no está el gato, el gato quisiera ser yo. (...) Quisiera tener su mirada de lejanía y verdor salvaje. (...) Quisiera ser gato como el gato, como mi gato. (...) Quisiera sus antenas (...) para vibrar con todo, con los más inaudibles movimientos del cielo" (Umbral, 2008, p. 52).

Concluimos diciendo que si, como en el Spleen baudeleriano visto anteriormente, la realidad es una ciudad lúgubre, y la vida, una batalla perdida ante el paso del tiempo y la muerte, la única manera de salvarse sería a través de la escritura y a través de la naturaleza felina. Charles Baudelaire y Francisco Umbral, con devoción absoluta hacia los gatos y con la intención de convertirse en uno de ellos para buscar, en medio de la tragedia cotidiana, cobijo en un delicado cojín, y cantar al sol en los atardeceres diarios, no querían más que vencer la muerte y perdurar en ese espacio indivisible del tiempo, en el presente puro, en esa línea infinita con que la Belleza costura la Eternidad.

\section{BIBLIOGRAFÍA}

Baudelaire, C. (1993). Las flores del mal (ed. A. Verjat y L. Martínez de Merlo, Trad. L. Martínez de Merlo). Madrid: Cátedra.

Baudelaire, C. (2006). Diarios íntimos (ed. y trad. J. Pedro Díaz). Buenos Aires: Leviatán.

Baudelaire, C. (2013). Pequeños Poemas en Prosa / Los Paraísos Artificiales (ed. y trad. J. A. Millán Alba). Madrid: Cátedra.

Jakobson, R. y Lévi-Strauss, C. (1970). "Los gatos" de Charles Baudelaire. En Sazbón, J. (ed.) Estructuralismo y literatura. Buenos Aires: Nueva Visión, pp. 11-34.
González-Ruano, C. (2008). Baudelaire. Barcelona: BlackList.

Umbral, F. (1985). La fábula del falo. Barcelona: Kairós.

Umbral, F. (1998). De lolas, viudas, gatos y Cervantes. El Mundo, 3 mayo 1998. [Fecha de consulta: 30/01/2014] Disponible en: http://www.elmundo.es/papel/ hemeroteca/1998/05/03/ultima/

Umbral, F. (1999). Trilogía de Madrid. Barcelona: Planeta.
Umbral, F. (2000). Los gatos. El Mundo, 8 abril 2000. [Fecha de consulta: 02/02/2014] Disponible en: http:// www.elmundo.es/especiales/2007/08/ cultura/umbral/columnas/2000.htm

Umbral, F. (2001). Un ser de lejanías. Barcelona: Planeta.

Umbral, F. (2008). Carta a mi mujer. Barcelona: Planeta.

Umbral, F. (2009). Obra poética (19812001) (ed. M. García-Posada). Barcelona: Seix Barral. 